\title{
High-definition endoscopy with digital chromoendoscopy for histologic prediction of distal colorectal polyps
}

Timo Rath', Gian E. Tontini ${ }^{1}$, Andreas Nägel ${ }^{1}$, Michael Vieth², Steffen Zopf ${ }^{1}$, Claudia Günther $^{1}$, Arthur Hoffman³ Markus F. Neurath ${ }^{1}$ and Helmut Neumann ${ }^{1 *}$

\begin{abstract}
Background: Distal diminutive colorectal polyps are common and accurate endoscopic prediction of hyperplastic or adenomatous polyp histology could reduce procedural time, costs and potential risks associated with the resection. Within this study we assessed whether digital chromoendoscopy can accurately predict the histology of distal diminutive colorectal polyps according to the ASGE PIVI statement.

Methods: In this prospective cohort study, 224 consecutive patients undergoing screening or surveillance colonoscopy were included. Real time histology of 121 diminutive distal colorectal polyps was evaluated using high-definition endoscopy with digital chromoendoscopy and the accuracy of predicting histology with digital chromoendoscopy was assessed.

Results: The overall accuracy of digital chromoendoscopy for prediction of adenomatous polyp histology was $90.1 \%$. Sensitivity, specificity, positive and negative predictive values were $93.3,88.7,88.7$, and $93.2 \%$, respectively. In high-confidence predictions, the accuracy increased to $96.3 \%$ while sensitivity, specificity, positive and negative predictive values were calculated as $98.1,94.4,94.5$, and $98.1 \%$, respectively. Surveillance intervals with digital chromoendoscopy were correctly predicted with $>90 \%$ accuracy.

Conclusions: High-definition endoscopy in combination with digital chromoendoscopy allowed real-time in vivo prediction of distal colorectal polyp histology and is accurate enough to leave distal colorectal polyps in place without resection or to resect and discard them without pathologic assessment. This approach has the potential to reduce costs and risks associated with the redundant removal of diminutive colorectal polyps.
\end{abstract}

Trial registration: ClinicalTrials NCT02217449.

Keywords: Adenomas, Colorectal cancer, Gastrointestinal endoscopy, Histology, Polyps

\section{Background}

Distal diminutive polyps (polyps $\leq 5 \mathrm{~mm}$ ) are frequently observed in daily clinical routine and can be found in more than $50 \%$ of the screening population $[1,2]$. However, diminutive polyps have a very low prevalence of advanced histologic features $[3,4]$ and their cancer prevalence ranges between 0 and $0.08 \%$ [5, 6]. Therefore, histology of diminutive polyps is mostly used to guide post-polypectomy surveillance. Since conventional

\footnotetext{
* Correspondence: helmut.neumann@uk-erlangen.de

'Interdisciplinary Endoscopy, Department of Medicine I, University Hospital Erlangen, Ulmenweg 18, 91054 Erlangen, Germany

Full list of author information is available at the end of the article
}

white-light endoscopy cannot reliably distinguish histological features of colorectal polyps, it is standard practice to remove all polyps for histopathological evaluation. However, this routine pathologic evaluation of all resected diminutive polyps results in considerable costs to the health care system for the management of a group of lesions which eventually have only limited clinical significance. The annual up-front cost savings in the US of forgoing the pathologic assessment would exceed one billion dollars per year [7].

Recently, the American Society for Gastrointestinal Endoscopy (ASGE) proposed two new paradigms for the management of diminutive polyps in the so called 
PIVI-statement [8]. One paradigm describes endoscopic resection of colorectal polyps without submitting them for pathological assessment ("resect and discard") while the other paradigm describes to leave diminutive hyperplastic rectosigmoid polyps in place without resection [8]. A prerequisite for both approaches is that an accurate real-time endoscopic assessment of the colorectal polyp histology could be made [8].

Within the recent years, dye-less chromoendoscopy techniques (DLC) are rapidly evolving allowing characterization of the tissue in real-time without the requirement of traditional dye-spraying. DLC includes optical (i.e. NBI, CBI) and digital (i.e. i-scan, FICE, SPIES) chromoendoscopy [9-12].

Recently, it was shown that NBI is reliable for in vivo prediction of distal polyp histology with a negative predictive value of $\geq 90 \%$ [13-16]. Nonetheless, data on the prediction of distal polyp histology with digital chromoendoscopy are scarce to date. Here, we prospectively assessed the potential of digital chromoendoscopy for real-time in vivo prediction of distal diminutive polyp histology according to the requirements of the ASGE PIVI statement.

\section{Methods}

\section{Study design, setting and patient recruitment}

We conducted a prospective observational study of diminutive polyps within the distal colorectum identified during screening or surveillance colonoscopies at the Ludwig Demling Endoscopy Center of Excellence at the University Hospital Erlangen. The study was approved by the local ethics committee (Ethical Commitee of the Medical Faculty of the Friedrich-Alexander University Erlangen-Nuremberg) and conforms to the provisions of the Declaration of Helsinki. ClinicalTrials Registration number is NCT02217449. Written informed consent was obtained from all patients prior to the procedure. Patients with a history of IBD, poor bowel preparation, colectomy, anticoagulation or polyposis syndrome were excluded.

\section{Endoscopic and histological assessment of polyps}

All colonoscopies were performed by a single experienced endoscopist. Polyps were defined as distal if located in the descending colon, the sigmoid colon, or the rectum. High-definition colonoscopes equipped with digital chromoendoscopy (Pentax, Tokyo, Japan) were used for all examinations. Upon visualization of a polyp in white-light, the location and size (as compared to open biopsy forceps or snare) were noted. Afterwards, i-scan was used to visualize and enhance the mucosal vascular pattern and the mucosal surface pattern of the polyp. The endoscopist made a real time assessment of each polyp according to size, shape, Paris classification [17] and surface characteristics including pit pattern and mucosal vascular pattern morphology, colour, and type of depression. Further, the endoscopist assigned a level of confidence (high or low) to each polyp [13, 16]. Afterwards, all polyps were resected using standard techniques and processed for pathological evaluation. Each polyp was assessed by an experienced GI pathologist blinded to the real time prediction of polyp histology. Finally, real time and histological results were compared.

\section{Variables and statistics}

Assessing the sensitivity and negative predictive value of digital chromoendoscopy for prediction of adenomatous polyp histology according to the recent PIVI statement [8] was the primary study endpoint. The pathology report was used as a reference point for the validation of the endoscopic assessment. Accuracy, diagnostic sensitivity and specificity and negative and positive prediction were calculated using SPPS 21.0 and are presented according to the STARD guidelines [18]. To assess the ability of i-scan to predict post-polypectomy surveillance intervals, the intervals that would be recommended by endoscopic prediction were compared with those that would be recommended by pathologic assessment as recommended in European [19] and US guidelines [20]. For this study we set the probability for error $(\alpha)$ to 0.05 and the $B$-error to 0.1 (reflecting a power of 0.90). For white light endoscopy, an expected accuracy of $74 \%$ and for i-scan an expected accuracy of $90 \%$ was assumed [21-23], resulting in a calculated sample size of 120 polyps. The intraobserver agreement was calculated by using the percentage agreement and the values of $\mathrm{K}$ statistics: slight, $\leq 0.2$; fair, $0.21-0.4$; moderate, 0.41-0.6; substantial, $0.61-0.80$; and almost perfect, $0.81-1.00$.

\section{Results}

\section{Study cohort}

224 consecutive patients undergoing screening or surveillance colonoscopy were prospectively included in the study. Of these, 77 patients had a total of 121 distal colorectal polyps. Of the 121 polyps, 42 were located in the descending colon, 32 in the sigmoid colon and 47 polyps were located in the rectum. Clinical, demographic and histologic characteristics of the patients and polyps are summarized in Table 1 . The median size of the polyps was $3 \mathrm{~mm}$ and all polyps studied were diminutive, thereby $\leq 5 \mathrm{~mm}$ in size. 63 polyps were nonadenomatous, of which almost all were hyperplastic by histology (62 out of 63) while 1 polyp was a leiomyoma. $47 \%$ of all polyps showed adenomatous histology (57 out of 121). Of these adenomas, the vast majority (46 out of 57) were tubular while seven adenomas exhibited 
Table 1 Clinical characteristics of the patients and polyps

\begin{tabular}{|c|c|c|}
\hline & \multicolumn{2}{|l|}{ Patient characteristics } \\
\hline & Patients with distal colorectal polyps $(n=77)$ & Patients with rectosigmoid polyps $(n=59)$ \\
\hline \multicolumn{3}{|l|}{ Sex, n (\%) } \\
\hline Male & 49 (63.6) & $37(62.7)$ \\
\hline Female & $28(36.4)$ & $22(37.3)$ \\
\hline \multicolumn{3}{|l|}{ Age, y } \\
\hline Mean \pm SD & $65.5 \pm 14.4$ & $61.9 \pm 15.2$ \\
\hline \multirow[t]{3}{*}{ Median (range) } & $67(22-83)$ & $66(22-83)$ \\
\hline & \multicolumn{2}{|l|}{ Polyp characteristics } \\
\hline & Polyps in the distal colorectum $(n=121)$ & Polyps in the rectosigmoid $(n=79)$ \\
\hline \multicolumn{3}{|l|}{ Location, n (\%) } \\
\hline Descending colon & $42(34.7)$ & \\
\hline Sigmoid & $32(26.5)$ & $32(40.5)$ \\
\hline Rectum & $47(38.8)$ & $47(59.5)$ \\
\hline \multicolumn{3}{|l|}{ Histology, n (\%) } \\
\hline Adenoma & $57(47.1)$ & $29(36.7)$ \\
\hline Tubular & $46(38)$ & $27(34.2)$ \\
\hline Tubulovillous & $7(5.8)$ & $2(2.5)$ \\
\hline SSA & $4(3.3)$ & $0(0)$ \\
\hline Hyperplastic & $63(52.1)$ & $50(63.3)$ \\
\hline Other (Leiomyoma) & $1(0.8)$ & \\
\hline \multicolumn{3}{|l|}{ Size, n (\%) } \\
\hline$\leq 3 \mathrm{~mm}$ & $75(62)$ & $54(68.4)$ \\
\hline $4-5 \mathrm{~mm}$ & $46(38)$ & $25(31.6)$ \\
\hline median (mean), mm & $3(3.3)$ & $3(3.2)$ \\
\hline
\end{tabular}

SSA, sessile serrated adenoma

tubulovillous histology. Further, four polyps were sessile serrated adenomas (SSAs) on histology, all of which were located in the descending colon.

\section{Diagnostic performances of real-time histologic predic- tion by digital chromoendoscopy}

Each polyp was characterized according to size, shape and surface characteristics (pit pattern and mucosal vascular pattern morphology, colour, depression; Fig. 1) before resection and in vivo histology was predicted with a level of confidence (high or low). The endoscopic distinction between hyperplastic and adenomatous polyps was made based upon previously published and validated criteria as shown in Table 2 [22].

Overall, the histology of 109 of the 121 polyps was predicted accurately through the real-time endoscopic appearance, leading to an accuracy of digital chromoendoscopy of $90.1 \%$. Of the 57 adenomas, only four were incorrectly predicted to be hyperplastic lesions, while 11 of the 63 non-adenomatous polyps were misdiagnosed as adenomas. As shown in Table 3, this equals a diagnostic sensitivity for real time assessment of $93.2 \%$ (95\% CI, 82.7-97.8), a specificity of 88.7 \% (95\% CI, 77.5-95) and a positive and negative prediction of $88.7 \%$ (95 \% CI, 77.5-95) and 93.2 \% (95 \% CI, 82.797.8), respectively. Intraobserver agreement was achieved in 113 out of 121 polyps (93.4\%), leading to an almost perfect $\mathrm{K}$ coefficient of agreement of $0.867 \quad$ [95\% CI: 0.799-0.967].

High confidence prediction of histology was made in 107 of 121 polyps (88.4\%). Considering only predictions made with high confidence, the accuracy of digital chromoendoscopy to predict histology was $96.3 \%$ (103 out of 107). When only predictions made with high confidence were considered, diagnostic performances were markedly increased with a diagnostic sensitivity for adenoma prediction of $98.1 \%$ (95 \% CI, 88.6-99.9) and a specificity of 94.4\% (95\% CI, 83.7-98.6). Likewise, positive and negative predictive values were also increased to $94.5 \%$ (95 \% CI, 83.9-98.6) and $98.1 \%$, (95\% CI, 88.4-99.1) respectively, when predictions were made with high confidence. Of note, all 4 SSAs 


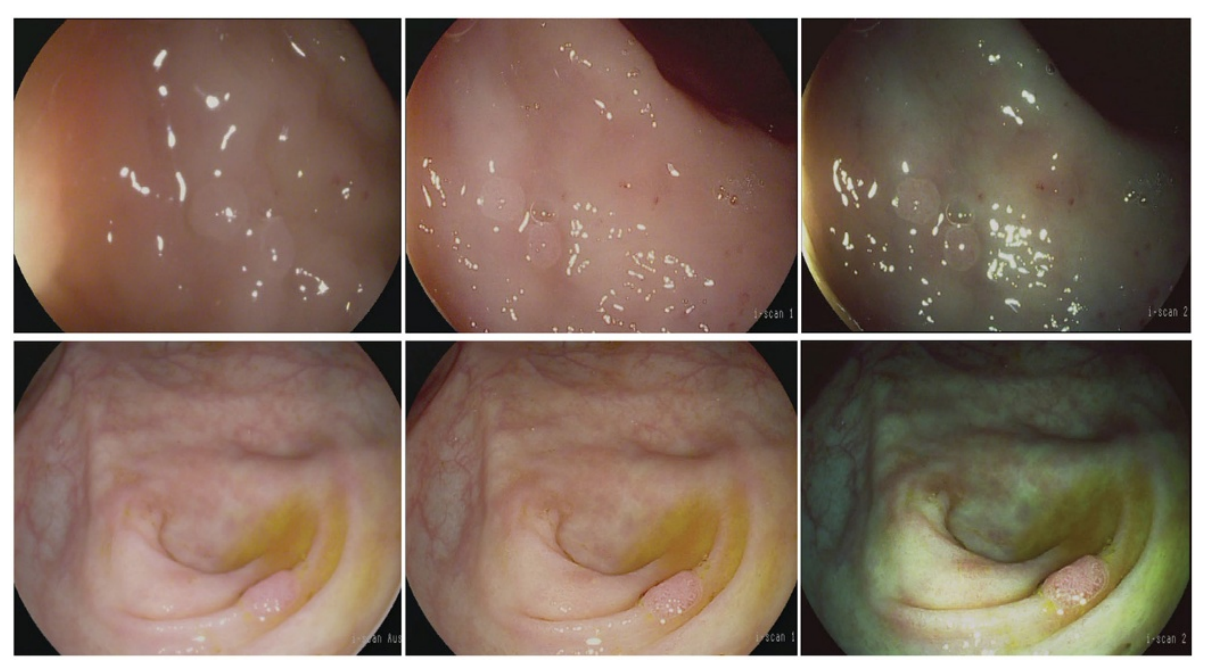

Fig. 1 High definition white light and digital chromoendoscopy of hyperplastic (upper panels) and adenomatous diminutive polyps (lower panels). Each polyp was characterized according to size, shape and surface characteristics including pit pattern and mucosal vascular pattern morphology, with digital chromoendoscopy before resection. The distinction between hyperplastic (upper panels) and adenomatous polyps (lower panels) was made based upon previously published and validated criteria on the appearance of diminutive colonic polyps under digital chromoendoscopy [22]. Left panels: High definition white light; Middle panel: High definition i-scan 1 (default setting); Right panel: High definition i-scan 2 (default setting)

were predicted be to adenomatous lesions by digital chromoendoscopy, and predictions were made with high confidence in all SSAs.

Since most of the studies evaluating the real-time assessment of polyp histology included only polyps located in the sigmoid and rectum and in order to allow direct comparability between the studies, we performed a subgroup analysis in our study cohort on the diagnostic performance of digital chromoendoscopy for prediction of histology in diminutive polyps of the rectum and sigmoid only. $36.7 \%$ ( 29 out of 79 ) of all polyps at this locale exhibited adenomatous histology while $63.3 \%$ (50 out of 79) were hyperplastic lesions (Table 1).

When only diminutive polyps in the rectosigmoid were considered, digital chromoendoscopy allowed prediction of adenomatous histology with a sensitivity of $90.3 \%$ (95\% CI, 73.1-97.5), a specificity of $87.5 \%$ (95\% CI, 74.1-94.8), a positive predictive value of $82.4 \%$ (95\% CI, 64.8-92.6) and a negative predictive value of $93.3 \%$ (95\% CI, 80.1-98.3) (Table 3). Importantly, when only high confidence predictions in the rectosigmoid were considered, diagnostic performances were again markedly increased and exhibited values comparable to those observed for all distal polyps (including descending colon) in which predictions were made with high confidence. The following diagnostic performances were calculated for high confidence predictions of polyps in the rectosigmoid: sensitivity $96.4 \%$ (95\% CI, 79.8-99.8), specificity $95.5 \%$ (95\% CI, 83.3-99.2), and positive and negative prediction of $93.1 \%(95 \% \mathrm{CI}, 75.8-98.8)$ and 97.7 \% (95 \% CI, 86.2-99.9), respectively.

\section{Prediction of future surveillance intervals}

Based on recent European [19] and US guidelines [20], we compared the predicted surveillance intervals made with in vivo assessment by digital chromoendoscopy with those made by standard histopathology. This analysis was done on a per-patient level, and according to the requirements of the PIVI only patients in which a high confidence prediction of polyp histology was possible were considered for this analysis.

Considering all distal polyps, surveillance based on European guidelines was predicted correctly in 69 out of 73 patients $(94.5 \%)$ while agreement was achieved in 68 out of 73 patients $(93.2 \%)$ when using the US guidelines.

When analyzing surveillance intervals in diminutive polyps in the rectosigmoid only, an accurate calculation

Table 2 Digital chromoendoscopy characteristics of diminutive colonic polyps [22]

\begin{tabular}{lll}
\hline & Hyperplasia & Adenoma \\
\hline Mucosal pattern & No definite pits; circular or dotted pits & Oval, tubular, or elongated pits \\
Vascular pattern & No visualized vessels or exiguous thin & Short, thick vessels with distinct vascular density surrounding \\
& superficial vessels & pits; overall increased vascular contrast compared to adjacent \\
& normal mucosa \\
\hline
\end{tabular}


Table 3 Diagnostic performances for histology predictions by using digital chromoendoscopy

\begin{tabular}{|c|c|c|c|c|c|}
\hline & \multicolumn{5}{|c|}{ Diagnostic performances } \\
\hline & Polyps (n) & Sensitivity $(95 \% \mathrm{Cl})$ & Specificity (95 \% Cl) & PPV $(95 \%$ Cl) & NPV $(95 \% \mathrm{Cl})$ \\
\hline \multicolumn{6}{|l|}{ All distal polyps } \\
\hline Overall prediction & 121 & $93.3 \%(82.7-97.8)$ & $88.7 \%(77.5-95)$ & $88.7 \%(77.5-95)$ & $93.2 \%(82.7-97.8)$ \\
\hline HC prediction & 107 & $98.1 \%(88.6-99.9)$ & $94.4 \%(83.7-98.6)$ & $94.5 \%(83.9-98.6)$ & $98.1 \%(88.4-99.9)$ \\
\hline \multicolumn{6}{|c|}{ Polyps in the rectosigmoid only } \\
\hline Overall prediction & 79 & $90.3 \%(73.1-97.5)$ & $87.5 \%(74.1-94.8)$ & $82.4 \%(64.8-92.6)$ & $93.3 \%(80.1-98.3)$ \\
\hline HC prediction & 72 & $96.4 \%$ (79.8-99.8) & $95.5 \%(83.3-99.2)$ & $93.1 \%(75.8-98.8)$ & $97.7 \%(86.2-99.9)$ \\
\hline
\end{tabular}

CI Confidence Interval, PPV Positive Predictive Value, NPV Negative Predictive Value, HC High Confidence

of surveillance intervals was possible in $96.4 \%$ of the patients (53 out of 55) with both, US and European guidelines. Patients in whom surveillance intervals predicted with in vivo assessment by digital chromoendoscopy differed compared to intervals as determined by standard histopathology are shown in Table 4.

\section{Discussion}

Here, we have shown that digital chromoendoscopy can reliable predict histology of distal diminutive polyps in real time according to the recommendations of the ASGE PIVI statement.

Distal diminutive colorectal polyps are common in the general screening population. Thus, an accurate endoscopic in vivo identification of polyps that are hyperplastic and therefore do not possess a risk of developing colorectal cancer is of major importance to reduce costs and risks associated with their redundant removal. Based on these considerations, the ASGE has proposed the PIVI statement on the real-time assessment of colorectal diminutive polyps [8] in which it is recommended that the technology used to guide the decision to leave a suspected hyperplastic polyp in the rectosigmoid in place should provide at least $90 \%$ negative prediction for adenomatous histology. Further, in order for diminutive colorectal polyps to be resected and discarded without pathologic examination, a new technology should provide $\mathrm{a} \geq 90 \%$ agreement with histopathologic assessment in assigning post-polypectomy intervals.

Within this study we thus set off to prospectively evaluate digital chromoendoscopy for the real-time in vivo assessment of distal diminutive colorectal polyps and specifically questioned whether digital chromoendoscopy is sufficiently accurate (i) to allow distal hyperplastic polyps to be left in place without resection or (ii) to be resected and discarded without pathological assessment. We found that digital chromoendoscopy is indeed able to differentiate adenomatous from non-adenomatous histology in real time with a high overall sensitivity and specificity. Importantly, digital chromoendoscopy exhibited a negative prediction for ruling out adenomas of $98 \%$ in high confidence predictions and predicted endoscopic surveillance intervals with $\geq 90 \%$ agreement compared to histology based US and European surveillance guidelines, thereby exceeding by far the thresholds recommended by the ASGE for leaving suspected hyperplastic polyps in place and for resecting and discarding diminutive polyps without pathologic

Table 4 Individual patients with discrepancies between predicted surveillance intervals made with in vivo assessment by digital chromoendoscopy and those made by standard histopathology

\begin{tabular}{|c|c|c|c|c|c|}
\hline & \multicolumn{2}{|c|}{$\begin{array}{l}\text { Pathology based surveillance intervals } \\
\text { (in years) }\end{array}$} & \multicolumn{2}{|c|}{$\begin{array}{l}\text { Endoscopy based surveillance intervals } \\
\text { (in years) }\end{array}$} & \multirow[t]{2}{*}{$\begin{array}{l}\text { Most advanced lesior } \\
\text { at pathology }\end{array}$} \\
\hline & European & US & European & US & \\
\hline \multicolumn{6}{|c|}{ All distal polyps } \\
\hline Patient 1 & 3 & 3 & 10 & 5 to 10 & Advanced adenoma \\
\hline Patient 2 & 3 & 3 & 10 & 5 to 10 & Advanced adenoma \\
\hline Patient 3 & 3 & 3 & 10 & 5 to 10 & Advanced adenoma \\
\hline Patient 4 & 3 & 3 & 10 & 5 to 10 & Advanced adenoma \\
\hline Patient 5 & 3 & 5 & 3 & 3 & SSA \\
\hline \multicolumn{6}{|c|}{ Rectosigmoid polyps } \\
\hline Patient 1 & 3 & 3 & 10 & 5 to 10 & Advanced adenoma \\
\hline Patient 2 & 3 & 3 & 10 & 5 to 10 & Advanced adenoma \\
\hline
\end{tabular}


assessment [8]. Of note, these values included diminutive polyps $\leq 5 \mathrm{~mm}$ of the rectum, sigma and descending colon. When focusing on polyps of the rectum and sigmoid colon only, digital chromoendoscopy exhibited an equally high diagnostic performance for both, the negative prediction of adenomatous histology and the prediction of surveillance intervals.

The results of this study are consistent with previous studies on optical chromoendoscopy which have shown that NBI can predict polyp histology in real-time with high accuracy $[14,16,24,25]$. Further, the available data illustrate that NBI indeed holds the potential to facilitate the management of distal diminutive polyps as it could accurately exclude adenomatous lesions with a sufficient negative prediction and also allowed for prediction of post polypectomy surveillance intervals in real time $[13,15,26]$.

Recently, it has been demonstrated that digital chromoendoscopy is superior compared to standard white-light colonoscopy for the detection of colorectal neoplasms [27], and a prospective cohort study demonstrated that NBI and i-scan exhibit a similar efficiency for the histological prediction of diminutive polyps [22]. Further, analyzing polyps throughout the whole colon, it was shown that digital chromoendoscopy could predict histology in diminutive colorectal polyps with high accuracy and could also predict surveillance intervals [21]. However, in this report high definition white-light endoscopy exhibited the same high negative prediction for adenomatous histology as digital chromoendoscopy [21]. As already discussed by the authors, the results of this study might exhibit a certain bias, as the study followed a strict protocol of cleaning all polyps with water, simethicone, and $\mathrm{N}$-acetylcysteine prior to the assessment of polyps [21].

Within this study, we included polyps of the distal colorectum and assessed them in real time under clinical conditions without pre-staining of the mucosa.

Importantly, our results show that the diagnostic performances of assessing histology are similar when all distal diminutive polyps were analyzed (including descending colon) or when the analysis was limited to diminutive polyps in the rectosigmoid only. These findings have important implications: Firstly, consistent with the results of the HiScope study [21], they provide further evidence that digital chromoendoscopy is indeed capable to translate the "leaving distal hyperplastic polyps in place" and "resect and discard" strategies into clinical practice, and secondly, they also allow a first insight that the "leaving in place" paradigm might not only be limited to polyps in the rectosigmoid, but could also be extended to the descending colon. However, the later aspect needs to be verified in a separate and large study cohort specifically addressing this question.
Although it has recently been suggested that SSAs may show changes in the microvasculature [28-30], their endoscopic identification and differentiation is challenging. Previous studies have shown that almost one third of all SSAs are misdiagnosed as hyperplastic polyps on NBI [31]. Since SSAs can progress to cancer through the serrated neoplasia pathway and can lead to sporadic microsatellite instability with a high colon cancer rate [32-34], their accurate endoscopic identification is of high clinical relevance. Although limited in number, all 4. SSAs included in the current study were correctly predicted be to adenomatous lesions by digital chromoendoscopy. Based on this, larger studies that assess whether digital chromoendoscopy can accurately predict SSA histology are highly warranted.

The strengths of this study are its prospective design and the assessment of a question that is highly relevant to daily endoscopic routine, and to which the answers are likely to influence and change daily practice. As a limitation, this study was conducted as a single center study and endoscopies were performed by a single endoscopist and it is anticipated that the interpretation of digital chromoendoscopy findings are also subject to inter-individual variations. Thus, studies in which lessexperienced and community physicians perform digital chromoendoscopy to predict histology of diminutive polyps will be needed before this approach becomes widely clinically accepted. Nevertheless, digital chromoendoscopy is, similar to NBI, a simple "push-of-abutton" technology and data on NBI illustrate that the appearance of adenomatous polyps can be learned within 15 to $20 \mathrm{~min}$ with moderate inter- and substantial intraobserver agreement [35-37]. Similarly, endoscopists with varying levels of experience can accurately predict polyp histology using digital chromoendoscopy after a single training session [38, 39] and digital chromoendoscopy exhibits comparable accuracies for the detection of colonic lesions by non-expert and expert endoscopists [40].

Further, we did not include a separate control arm assessing whether high-definition endoscopy without the concomitant utilization of digital chromoendoscopy can adequately predict polyp histology. However, it has been shown recently that the adenoma detection rate does not differ between procedures utilizing high-definition or standard-definition endoscopes [41]. Further, it is known that high definition endoscopy in combination with digital chromoendoscopy is superior compared to white-light colonoscopy for the detection of colorectal neoplasms [27]. Based on these existing data, we thus aimed to address the remaining question whether high definition endoscopy in combination with digital chromoendoscopy is accurate to predict real time polyp histology, a question which can be well addressed with the 
design of our study. Nevertheless, it seems clear that in the future multi-center and multi-observer studies including experts and non-expert endoscopists should be performed to assess the inter-observer agreement and accuracy for predicting histology and also to assess the learning curve for predicting histology in diminutive colonic polyps using digital chromoendoscopic modalities. Further, it is important to demonstrate in the future that digital chromoendoscopy is as precise as optical chromoendoscopy and conventional dye based endoscopy.

\section{Conclusion}

In summary, we have shown that digital chromoendoscopy allows an accurate real time prediction of the histology of diminutive polyps in the distal colon and by far exceed the thresholds recommended by the ASGE for a new technology to leave diminutive polyps in place or to resect and discard them without pathological assessment. Based on our results, further studies on the prediction of polyp histology with digital chromoendoscopy should be performed with the inclusion of less experienced physicians and polyps of the whole colon.

\section{Abbreviations \\ CRC: Colorectal cancer; ASGE: American Society for Gastrointestinal Endoscopy; PIVI: Preservation and incorporation of valuable endoscopic innovations; DLC: Dye-less chromoendoscopy; NBI: Narrow band imaging; CBI: Compound band imaging; FICE: Fuji intelligent color enhancement; SPIES: Storz professional image enhancement systems; Cl: Confidence interval; PPV: Positive predictive value; NPV: Negative predictive value; HC: High confidence.}

\section{Competing interests}

Financial competing interests: The authors declare that they have no competing financial interests.

Non-Financial competing interests: The authors declare that they have no competing non-financial interests.

\section{Authors' contributions}

TR analyzed the data and prepared the manuscript. HN, MFN designed the study, analyzed the data and prepared the manuscript. GET, AN, SZ, AH provided critical help in polyp collection during endoscopy. CG analyzed data and revised the manuscript. MV assessed polyp histology. All authors read and approved the final manuscript.

\section{Acknowledgement}

The authors acknowledge support by Deutsche Forschungsgemeinschaft (DFG) and Friedrich-Alexander-University Erlangen-Nuremberg (FAU) within the funding programme Open Access Publishing. Timo Rath received funding from the Erlangen Interdisciplinary Center for Clinical Research (IZKF). Gian Eugenio Tontini is the recipient of a grant from the Italian Group for the study of IBD (IG-IBD) to support his research work at the Department of Medicine I, University of Erlangen-Nuremberg.

\footnotetext{
Author details

${ }^{1}$ Interdisciplinary Endoscopy, Department of Medicine I, University Hospital Erlangen, Ulmenweg 18, 91054 Erlangen, Germany. ${ }^{2}$ Institute of Pathology, Klinikum Bayreuth, Bayreuth, Germany. ${ }^{3}$ Department of Medicine II, HSK Wiesbaden, Wiesbaden, Germany.
}

Received: 27 May 2015 Accepted: 13 October 2015

Published online: 22 October 2015

\section{References}

1. Kahi CJ, Anderson JC, Waxman I, Kessler WR, Imperiale TF, Li X, et al. High-definition chromocolonoscopy vs. high-definition white light colonoscopy for average-risk colorectal cancer screening. Am J Gastroenterol. 2010;105(6):1301-7.

2. Rex DK, Helbig CC. High yields of small and flat adenomas with highdefinition colonoscopes using either white light or narrow band imaging. Gastroenterology. 2007;133(1):42-7.

3. Gupta N, Bansal A, Rao D, Early DS, Jonnalagadda S, Wani SB, et al. Prevalence of advanced histological features in diminutive and small colon polyps. Gastrointest Endosc. 2012;75(5):1022-30.

4. O'Brien MJ, Winawer SJ, Zauber AG, Gottlieb LS, Sternberg SS, Diaz B, et al. The National Polyp Study. Patient and polyp characteristics associated with high-grade dysplasia in colorectal adenomas. Gastroenterology. 1990;98(2):371-9.

5. Butterly LF, Chase MP, Pohl H, Fiarman GS. Prevalence of clinically important histology in small adenomas. Clin Gastroenterol Hepatol. 2006;4(3):343-8.

6. Lieberman D, Moravec M, Holub J, Michaels L, Eisen G. Polyp size and advanced histology in patients undergoing colonoscopy screening: implications for CT colonography. Gastroenterology. 2008;135(4):1100-5.

7. Kessler WR, Imperiale TF, Klein RW, Wielage RC, Rex DK. A quantitative assessment of the risks and cost savings of forgoing histologic examination of diminutive polyps. Endoscopy. 2011;43(8):683-91.

8. Rex DK, Kahi C, O'Brien M, Levin TR, Pohl H, Rastogi A, et al. The American Society for Gastrointestinal Endoscopy PIVI (Preservation and Incorporation of Valuable Endoscopic Innovations) on real-time endoscopic assessment of the histology of diminutive colorectal polyps. Gastrointest Endosc. 2011;73(3):419-22

9. Galloro G. High technology imaging in digestive endoscopy. World J Gastrointest Endosc. 2012:4(2):22-7.

10. Neumann H, Fujishiro M, Wilcox CM, Monkemuller K. Present and future perspectives of virtual chromoendoscopy with i-scan and optical enhancement technology. Dig Endosc. 2014;26 Suppl 1:43-51.

11. Neumann $\mathrm{H}$, Neurath MF, Mudter J. New endoscopic approaches in IBD. World J Gastroenterol. 2011;17(1):63-8.

12. Tontini GE, Vecchi M, Neurath MF, Neumann H. Review article: newer optical and digital chromoendoscopy techniques vs. dye-based chromoendoscopy for diagnosis and surveillance in inflammatory bowel disease. Aliment Pharmacol Ther. 2013;38(10):1198-208.

13. Hewett DG, Huffman ME, Rex DK. Leaving distal colorectal hyperplastic polyps in place can be achieved with high accuracy by using narrow-band imaging: an observational study. Gastrointest Endosc. 2012;76(2):374-80

14. Rastogi A, Keighley J, Singh V, Callahan P, Bansal A, Wani S, et al. High accuracy of narrow band imaging without magnification for the real-time characterization of polyp histology and its comparison with high-definition white light colonoscopy: a prospective study. Am J Gastroenterol. 2009;104(10):2422-30.

15. Repici A, Hassan C, Radaelli F, Occhipinti P, De Angelis C, Romeo F, et al. Accuracy of narrow-band imaging in predicting colonoscopy surveillance intervals and histology of distal diminutive polyps: results from a multicenter, prospective trial. Gastrointest Endosc. 2013;78(1):106-14.

16. Rex DK. Narrow-band imaging without optical magnification for histologic analysis of colorectal polyps. Gastroenterology. 2009;136(4):1174-81.

17. The Paris endoscopic classification of superficial neoplastic lesions: esophagus, stomach, and colon: November 30 to December 1, 2002 Gastrointest Endosc. 2003, 58(6 Suppl):S3-43.

18. Bossuyt PM, Reitsma JB, Bruns DE, Gatsonis CA, Glasziou PP, Irwig LM, et al. Towards complete and accurate reporting of studies of diagnostic accuracy: The STARD Initiative. Ann Intern Med. 2003;138(1):40-4.

19. Atkin WS, Valori R, Kuipers EJ, Hoff G, Senore C, Segnan N, et al. European guidelines for quality assurance in colorectal cancer screening and diagnosis. First Edition-Colonoscopic surveillance following adenoma removal. Endoscopy. 2012:44 Suppl 3:SE151-163.

20. Lieberman DA, Rex DK, Winawer SJ, Giardiello FM, Johnson DA, Levin TR. Guidelines for colonoscopy surveillance after screening and polypectomy: a consensus update by the US Multi-Society Task Force on Colorectal Cancer. Gastroenterology. 2012;143(3):844-57.

21. Basford PJ, Longcroft-Wheaton G, Higgins B, Bhandari P. High-definition endoscopy with i-Scan for evaluation of small colon polyps: the HiSCOPE study. Gastrointest Endosc. 2014;79(1):111-8. 
22. Lee CK, Lee SH, Hwangbo Y. Narrow-band imaging versus I-Scan for the real-time histological prediction of diminutive colonic polyps: a prospective comparative study by using the simple unified endoscopic classification. Gastrointest Endosc. 2011;74(3):603-9.

23. Rastogi A, Early DS, Gupta N, Bansal A, Singh V, Ansstas M, et al. Randomized, controlled trial of standard-definition white-light, highdefinition white-light, and narrow-band imaging colonoscopy for the detection of colon polyps and prediction of polyp histology. Gastrointest Endosc. 2011;74(3):593-602.

24. Rogart JN, Jain D, Siddiqui UD, Oren T, Lim J, Jamidar P, et al. Narrow-band imaging without high magnification to differentiate polyps during real-time colonoscopy: improvement with experience. Gastrointest Endosc. 2008;68(6):1136-45.

25. Sikka S, Ringold DA, Jonnalagadda S, Banerjee B. Comparison of white light and narrow band high definition images in predicting colon polyp histology, using standard colonoscopes without optical magnification. Endoscopy. 2008;40(10):818-22.

26. Gupta N, Bansal A, Rao D, Early DS, Jonnalagadda S, Edmundowicz SA, et al. Accuracy of in vivo optical diagnosis of colon polyp histology by narrow-band imaging in predicting colonoscopy surveillance intervals. Gastrointest Endosc. 2012;75(3):494-502.

27. Hoffman A, Sar F, Goetz M, Tresch A, Mudter J, Biesterfeld S, et al. High definition colonoscopy combined with i-Scan is superior in the detection of colorectal neoplasias compared with standard video colonoscopy: a prospective randomized controlled trial. Endoscopy. 2010;42(10):827-33.

28. Hazewinkel Y, East JE, Dekker E. Response. Gastrointest Endosc. 2014;79(1):184

29. Hazewinkel Y, Lopez-Ceron M, East JE, Rastogi A, Pellise M, Nakajima T, et al. Endoscopic features of sessile serrated adenomas: validation by international experts using high-resolution white-light endoscopy and narrow-band imaging. Gastrointest Endosc. 2013;77(6):916-24.

30. lacucci M, Xianyong G, Love J, Eustace G, Ghosh S. Novel irregular vascular pattern features of serrated adenoma detected by high-definition iScan endoscopic technique. Gastrointest Endosc. 2014;79(1):182-4.

31. Kumar S, Fioritto A, Mitani A, Desai M, Gunaratnam N, Ladabaum U. Optical biopsy of sessile serrated adenomas: do these lesions resemble hyperplastic polyps under narrow-band imaging? Gastrointest Endosc. 2013;78(6):902-9.

32. O'Brien MJ, Yang S, Clebanoff JL, Mulcahy E, Farraye FA, Amorosino M, et al. Hyperplastic (serrated) polyps of the colorectum: relationship of CpG island methylator phenotype and K-ras mutation to location and histologic subtype. Am J Surg Pathol. 2004;28(4):423-34.

33. O'Brien MJ, Yang S, Mack C, Xu H, Huang CS, Mulcahy E, et al. Comparison of microsatellite instability, CpG island methylation phenotype, BRAF and KRAS status in serrated polyps and traditional adenomas indicates separate pathways to distinct colorectal carcinoma end points. Am J Surg Pathol. 2006;30(12):1491-501.

34. Rosenberg DW, Yang S, Pleau DC, Greenspan EJ, Stevens RG, Rajan TV, et al. Mutations in BRAF and KRAS differentially distinguish serrated versus nonserrated hyperplastic aberrant crypt foci in humans. Cancer Res. 2007:67(8):3551-4.

35. Ignjatovic A, Thomas-Gibson S, East JE, Haycock A, Bassett P, Bhandari P, et al. Development and validation of a training module on the use of narrow-band imaging in differentiation of small adenomas from hyperplastic colorectal polyps. Gastrointest Endosc. 2011;73(1):128-33.

36. Raghavendra M, Hewett DG, Rex DK. Differentiating adenomas from hyperplastic colorectal polyps: narrow-band imaging can be learned in 20 minutes. Gastrointest Endosc. 2010;72(3):572-6.

37. Rastogi A, Pondugula K, Bansal A, Wani S, Keighley J, Sugar J, et al. Recognition of surface mucosal and vascular patterns of colon polyps by using narrow-band imaging: interobserver and intraobserver agreement and prediction of polyp histology. Gastrointest Endosc. 2009;69(3 Pt 2):716-22.

38. Bouwens MW, de Ridder R, Masclee AA, Driessen A, Riedl RG, Winkens $B$, et al. Optical diagnosis of colorectal polyps using high-definition i-scan: an educational experience. World J Gastroenterol. 2013;19(27):4334-43.

39. Neumann H, Vieth M, Fry LC, Gunther C, Atreya R, Neurath MF, et al. Learning curve of virtual chromoendoscopy for the prediction of hyperplastic and adenomatous colorectal lesions: a prospective 2-center study. Gastrointest Endosc. 2013;78(1):115-20.
40. Testoni PA, Notaristefano C, Di Leo M, Vailati C, Mazzoleni G, Viale E. High-definition with i-Scan gives comparable accuracy for detecting colonic lesions by non-expert and expert endoscopists. Dig Liver Dis. 2013;45(6):481-6.

41. Gomez V, Racho RG, Heckman MG, Diehl NN, Wallace MB. High-Definition White-Light (HDWL) colonoscopy and higher adenoma detection rate and the potential for paradoxical over surveillance. Dig Dis Sci. 2014;59(11):2749-56.

\section{Submit your next manuscript to BioMed Central and take full advantage of:}

- Convenient online submission

- Thorough peer review

- No space constraints or color figure charges

- Immediate publication on acceptance

- Inclusion in PubMed, CAS, Scopus and Google Scholar

- Research which is freely available for redistribution 